\title{
Liquid chromatography-tandem mass spectrometry determination of synthetic cathinones and phenethylamines in influent wastewater of eight European cities
}

Richard Bade ${ }^{\mathrm{a}}$, Lubertus Bijlsma ${ }^{\mathrm{a}}$, Juan V. Sancho ${ }^{\mathrm{a}}$, Jose A. Baz-Lomba ${ }^{\mathrm{b}, \mathrm{c}}$, Sara Castiglioni $^{\mathrm{d}}$, Erika Castrignanò ${ }^{\mathrm{e}}$, Ana Causanilles ${ }^{\mathrm{f}}$, Emma Gracia-Lor ${ }^{\mathrm{a}, \mathrm{d}}$, Barbara Kasprzyk-Hordern ${ }^{\mathrm{e}}$, Juliet Kinyua ${ }^{\mathrm{h}}$, Ann-Kathrin McCalli, Alexander L.N. van Nuijs ${ }^{\mathrm{h}}$, Christoph Ort ${ }^{\mathrm{i}}$, Benedek G. Plósz ${ }^{\mathrm{j}}$, Pedram Ramin ${ }^{\mathrm{j}}$, Nikolaos I. Rousis ${ }^{\mathrm{d}}$, Yeonsuk Ryu $^{\mathrm{b}, \mathrm{c}}$, Kevin V. Thomas ${ }^{\mathrm{b}}$, Pim de Voogt ${ }^{\mathrm{f}, \mathrm{g}}$, Ettore Zuccato ${ }^{\mathrm{d}}$, Félix Hernández ${ }^{\mathrm{a}, *}$

${ }^{a}$ Research Institute for Pesticides and Water, University Jaume I, Avda. Sos Baynat s/n, E-12071 Castellón, Spain.

${ }^{\mathrm{b}}$ Norwegian Institute for Water Research (NIVA), Gaustadalléen 21, 0349 Oslo,

Norway

${ }^{\mathrm{c}}$ Faculty of Medicine, University of Oslo, PO box 1078 Blindern, 0316, Oslo, Norway

${ }^{\mathrm{d}}$ IRCCS - Istituto di Ricerche Farmacologiche "Mario Negri”, Department of

Environmental Health Sciences, Via La Masa 19, 20156 Milan, Italy

e University of Bath, Department of Chemistry, Faculty of Science, Bath BA2 7AY, UK ${ }^{\mathrm{f}}$ KWR Watercycle Research Institute, Chemical Water Quality and Health, P.O. Box 1072, 3430 BB, Nieuwegein, The Netherlands

${ }^{\mathrm{g}}$ Institute for Biodiversity and Ecosystem Dynamics, University of Amsterdam, P.O. Box 94248, 1090 GE, Amsterdam, The Netherlands

h Toxicological Center, Department of Pharmaceutical Sciences, Campus Drie Eiken, University of Antwerp, Universiteitsplein 1, 2610 Antwerp, Belgium

i Eawag, Swiss Federal Institute of Aquatic Science and Technology, CH-8600, Dübendorf, Switzerland

j Department of Environmental Engineering, Technical University of Denmark, Miljøvej, Building 115, DK-2800 Kgs. Lyngby, Denmark

*Corresponding author: felix.hernandez@uji.es Tel.: +34 964387366 Fax: +34 964 387368 
The popularity of new psychoactive substances (NPS) has grown in recent years, with certain NPS commonly and preferentially consumed even following the introduction of preventative legislation. With the objective to improve the knowledge on the use of NPS, a rapid and very sensitive method was developed for the determination of ten priority NPS (N-ethylcathinone, methylenedioxypyrovalerone (MDPV), methylone, butylone, methedrone, mephedrone, naphyrone, 25-C-NBOMe, 25-I-NBOMe and 25-BNBOMe) in influent wastewater. Sample clean-up and pre-concentration was made by off-line solid phase extraction (SPE) with Oasis MCX cartridges. Isotopically labelled internal standards were used to correct for matrix effects and potential SPE losses. Following chromatographic separation on a $\mathrm{C}_{18}$ column within 6 minutes, the compounds were measured by tandem mass spectrometry in positive ionisation mode. The method was optimised and validated for all compounds. Limits of quantification were evaluated by spiking influent wastewater samples at 1 or $5 \mathrm{ng} / \mathrm{L}$. An investigation into the stability of these compounds in influent wastewater was also performed, showing that, following acidification at $\mathrm{pH} 2$, all compounds were relatively stable for up to 7 days. The method was then applied to influent wastewater samples from eight European countries, in which mephedrone, methylone and MDPV were detected. This work reveals that although NPS use is not as extensive as for classic illicit drugs, the application of a highly sensitive analytical procedure makes their detection in wastewater possible. The developed analytical methodology forms the basis of a subsequent model-based back-calculation of abuse rate in urban areas (i.e. wastewaterbased epidemiology). 
57 Key Words: New psychoactive substances, Ultra high-performance liquid 58 chromatography, Triple Quadrupole, Wastewater, Stability, Matrix Effects 
60

61

New psychoactive substances (NPS) are emerging narcotic or psychotropic drugs that are not controlled by legislation, but which may pose a public health threat. It must be noted that here, the term 'new' does not necessarily refer to new inventions but to substances that have recently become available (UNODC, 2014). The use of NPS has grown rapidly over the past decade and there have been increasing reports of the availability and manufacture of such substances, with the number of NPS reported globally more than doubling between 2009-2013 (UNODC 2014). In 2014 alone, 101 NPS were for the first time reported to the EU Early Warning System (EMCDDA, 2015a). Given the nature of the NPS market, with developers limited only by their imagination and ability to side-step legislation (Reid and Thomas, 2016) there is a sustained need to analyse the extent of the NPS problem.

The analysis of wastewater to estimate (illicit) drug consumption based on biomarkers, has traditionally focussed on the most common illicit drugs - cocaine, cannabis, amphetamine, methamphetamine and 3,4-methylenedioxymethamphetamine (ecstasy, MDMA) (Ort et al., 2014; Thomas et al., 2012), leaving a large information gap on other illicit drugs and NPS. Little research has been made on NPS and their suitable biomarkers, let alone their stability. In the few papers that have been published until now on the determination of NPS in wastewater, the target analytes included are commonly the synthetic cathinones mephedrone, methylone and MDPV (Baz-Lomba et al., 2016; Borova et al., 2015; Castrignanò et al., 2016; Chen et al., 2013; Kankaanpää et al., 2014; Kinyua et al., 2015a; Mwenesongole et al., 2013; Reid et al., 2014; Senta et al., 2015; van Nuijs et al., 2013). Within these studies, the most commonly detected NPS in wastewater are mephedrone and MDPV, generally found at the low ng/L range. 
Liquid chromatography coupled to tandem mass spectrometry (LC-MS/MS) is the technique of choice for the quantitative determination of illicit drugs in wastewater, due to the low concentrations involved and the high sensitivity of the instrument. In addition to the required validation at realistic concentrations that can be found in the samples, relevant issues must be considered, such as the way to correct/minimize matrix effects, and the proper identification of the compound detected. The use of isotopically-labelled internal standards (ILIS) is one of the most efficient tools to correct for matrix effects as well as potential losses from solid phase extraction (SPE). When utilising LC-MS/MS instruments in selected reaction monitoring (SRM) mode, at least two transitions should be incorporated in the method (one for quantification and the other(s) for confirmation). However, the specificity of the transitions should be taken into account, as non-specific transitions (such as the loss of water) can lead to false negatives due to the noncompliance of ion ratios (Pozo et al., 2006).

The purpose of this study was to develop and validate a sensitive LC-MS/MS method for the quantitative determination of a number of NPS of the synthetic cathinone and phenethylamine families: butylone, ethylone, methylone, naphyrone, methedrone, methylenedioxypyrovalerone (MDPV), mephedrone, 25-I-NBOMe, 25-C-NBOMe and 25-B-NBOMe. These compounds were selected on the basis of their frequent detection in analytical, forensic and toxicological studies (Borova et al., 2015; Chen et al., 2013; Elliott and Evans, 2014; Ibáñez et al., 2014; Kankaanpää et al., 2014; Kinyua et al., 2015a; Mwenesongole et al., 2013; Reid et al., 2014; Senta et al., 2015; Uralets et al., 2014) as well as reports from the EMCDDA (EMCDDA, 2015b) and UNODC (UNODC, 2014). The developed method, using Oasis MCX SPE cartridges for sample pre-treatment, followed by UHPLC-MS/MS measurement, has been applied to influent wastewater samples from around Europe, with an additional study on stability being 
made. Special emphasis is placed on the reliable confirmation of the NPS detected in 109 water, with up to three SRM transitions being acquired, which, together with ion ratios, 110 allowed simultaneous detection, quantification and confirmation of positive samples. 


\section{Experimental}

\subsection{Chemicals and Materials}

113 See Supporting Information for this section as well as the structures of all compounds 114 (Figure S1).

\subsection{Samples}

116 A number of different influent wastewater (IWW) samples were utilised in the 117 development and validation of the present method: from Zurich, Switzerland; 118 Copenhagen, Denmark and Castellon, Spain. The developed method was applied to 119 IWW samples. The 24-h composite samples were taken in March 2015 from Zurich, 120 Switzerland; Copenhagen, Denmark; Oslo, Norway; Castellon, Spain; Milan, Italy; 121 Brussels, Belgium, Utrecht, The Netherlands and Bristol, United Kindom. All samples were collected in high density polyethylene bottles, transported to Castellon and stored in the dark at $-20^{\circ} \mathrm{C}$ until pre-treatment.

\subsection{Instrumentation}

125 A Waters Acquity UHPLC system (Milford, MA, USA) was interfaced to a triple quadrupole mass spectrometer (Xevo TQS, Waters Micromass, Manchester, UK) equipped with Z-Wave devices and an electrospray ionization interface (ESI) operated 128 in positive-ion mode. The chromatographic separation was performed using an Acquity 129 UPLC BEH $\mathrm{C}_{18}$ column, $1.7 \mu \mathrm{m}, 50 \mathrm{~mm} \times 2.1 \mathrm{~mm}$ (i.d.) (Waters) at a flow rate of 0.3 $130 \mathrm{~mL} \min ^{-1}$. The mobile phases used were water with $5 \mathrm{mM}$ ammonium acetate and $0.01 \%$ formic acid (solvent $\mathrm{A}$ ) and $\mathrm{MeOH}$ with $0.01 \%$ formic acid (solvent $\mathrm{B}$ ). The

132 percentage of $\mathrm{B}$ changed linearly as follows: $0 \mathrm{~min}, 10 \% ; 3 \mathrm{~min}, 90 \% ; 3.5 \mathrm{~min}, 90 \%$;

$1333.6 \mathrm{~min}, 10 \%$; 6 min $10 \%$, equilibration of the column. Cone gas as well as desolvation 
134 gas was dry nitrogen, with flows set to 150 and $800 \mathrm{~L} \mathrm{~h}^{-1}$, respectively. For operation in 135 MS/MS mode, collision gas was argon $99.995 \%$ (Praxair, Madrid, Spain) with a 136 pressure of $4 \times 10^{-3}$ mbar in the collision cell $\left(0.15 \mathrm{~mL} \mathrm{~min}^{-1}\right)$. Further parameters 137 optimized were: capillary voltage, $3.0 \mathrm{kV}$; source temperature, $150{ }^{\circ} \mathrm{C}$ and desolvation 138 temperature, $650{ }^{\circ} \mathrm{C}$. Dwell times of $0.01 \mathrm{~s} /$ transition were automatically selected.

139 All acquired data were processed using MassLynx v4.1 software (Waters, Manchester, $140 \mathrm{UK})$.

\subsection{Sample Pre-treatment}

142 All water samples were acidified to $\mathrm{pH} 2$ with formic acid (98\%), then centrifuged for 5 143 minutes at $6000 \mathrm{rpm}$. SPE cartridges were conditioned with methanol $(6 \mathrm{~mL})$, water 144 (3mL) and acidified water (pH 2 with formic acid, 3mL). The IWW samples (100mL) 145 were spiked with mixed surrogate ILIS to give a final in sample concentration of 20 $146 \mathrm{ng} / \mathrm{L}$, then percolated through the cartridges at $\pm 5 \mathrm{~mL} / \mathrm{min}$. The cartridges were then 147 washed with $5 \mathrm{~mL}$ acidified methanol ( $\mathrm{pH} 2$ with formic acid) and dried under vacuum 148 for 10 minutes. The analytes were eluted with $5 \mathrm{~mL} \mathrm{MeOH} \mathrm{(2 \%} \mathrm{ammonia),} \mathrm{evaporated}$ 149 to dryness at $35^{\circ} \mathrm{C}$ under nitrogen and reconstituted to $1 \mathrm{~mL}$ with 10:90 methanol:water.

150 Analyses were performed by injecting $3 \mu \mathrm{L}$ of the final extract in the UHPLC-MS/MS 151 system. 


\subsection{Quantification and Method Validation}

SRM mode was used to acquire all data, with the precursor ion of each compound being the protonated molecule. In general, the most abundant product ion of each target analyte was used for quantification, with one or two additional product ions and their ion ratios used for confirmation. Furthermore, LC retention time was compared to that of reference standards (tolerance of \pm 0.1 minutes). These steps are in line with the SANCO guidelines for analytical quality control and validation procedures (SANCO, 2013), which has been utilised previously by research groups for quantification of illicit drugs in wastewater (Bijlsma et al., 2009). Each compound was quantified using its ILIS as a surrogate internal standard, except N-ethylcathinone and methedrone, which were quantified using butylone- $\mathrm{d}_{3}$ and methylone- $\mathrm{d}_{3}$, respectively. These ILIS were chosen based on their ability to correct for matrix effects as well as having similar retention times and chemical structures closely related to the analyte of interest.

The performance of the method was evaluated in terms of linearity, limits of detection and quantification, accuracy and precision.

The linearity was studied by analysing standard solutions in solvent in triplicate at seven concentration levels ranging from $0.5-100 \mathrm{ng} / \mathrm{L}$. Linearity was deemed satisfactory when the correlation coefficient (r) was $>0.99$, using weighted (1/X) least squares regression.

For limits of quantification and detection (LOQ and LOD), two different concentration levels ( 1 and $5 \mathrm{ng} / \mathrm{L}$ ) were tested so as to provide a more accurate measure. The limit of quantification (LOQ) was established as the lowest level for which the method was fully validated using spiked IWW samples with satisfactory accuracy based on recovery experiments (between 70-120\%) and precision (relative standard deviation (RSD) 
$176 \leq 20 \%$ ). Furthermore, a minimum of two MS/MS transitions were required at the LOQ

177 level for confirmation. All recovery experiments were performed in quintuplicate.

178 The limit of detection (LOD) was estimated using blank samples spiked at the lowest

179 analyte concentration tested, based on a signal-to-noise level of three from the 180 quantification SRM chromatogram. 
182 Stability experiments were performed under different conditions (IWW at natural $\mathrm{pH}$ 183 and acidified to $\mathrm{pH} 2$, filtered influent wastewater at natural $\mathrm{pH}$ and acidified to $\mathrm{pH} 2$ 184 and MilliQ water) and at three different temperatures $\left(20^{\circ} \mathrm{C}, 4^{\circ} \mathrm{C}\right.$ and $\left.-20^{\circ} \mathrm{C}\right)$ for 24 185 hours, 48 hours, 7 days, and 30 days (at $-20^{\circ} \mathrm{C}$ only). The samples were each initially 186 spiked at a concentration level of $100 \mathrm{ng} / \mathrm{L}$. One $\mathrm{mL}$ of each sample was collected at the 187 time intervals outlined above and spiked with ILIS (100 ng/L) just before analysis. 


\section{Results and Discussion}

\subsection{Selection of Compounds}

Only parent compounds were selected for this study. This is based on the previous metabolism studies performed on the selected ten as well as related NPS in human and rat urine (Caspar et al., 2015; Ibáñez et al., 2016; Kamata et al., 2006; Mardal and Meyer, 2014; Meyer et al., 2010; Uralets et al., 2014), which showed that in spite of the number of metabolites identified, the parent compound could still be detected in urine.

It has also been shown that the metabolic patterns of selected phenethylamine-based designer drugs show rather slow metabolism rates, with parent drugs being the primary biomarkers of consumption (Lai et al., 2015; Senta et al., 2015), somewhat expected due to their structural similarity to amphetamine and MDMA (Ort et al., 2014).

In addition, for the phenethylamine-based 25-X-NBOMe compounds, the parent compound is generally used in both qualitative and quantitative toxicological studies (Kinyua et al., 2015b; Poklis et al., 2014; Tang et al., 2014).

\subsection{Instrument Optimisation}

204

Initially, all cone voltages were optimised concurrently for all compounds, using a mixed standard solution $(10 \mu \mathrm{g} / \mathrm{L})$, with the cone voltage ranging from $10-50 \mathrm{~V}$ at $10 \mathrm{~V}$ intervals. For all compounds, the precursor ion was $[\mathrm{M}+\mathrm{H}]^{+}$. Collision energies were optimised for each compound independently using a collision energy ranging from 10$50 \mathrm{eV}$ at $10 \mathrm{eV}$ intervals. The most sensitive transition was typically selected for quantification (Q) while an additional one (or two) were selected for confirmation (q). transitions such as the loss of water were avoided as much as possible (except for 
methylone, mephedrone and N-ethylcathinone where they were used as confirmation transitions) in order to reduce the likelihood of false positives (Bijlsma et al., 2009). For the three 25-X-NBOMe compounds, the same product ions were seen $(\mathrm{m} / \mathrm{z} 121$ and 91$)$, corresponding to the cleavage of the methoxybenzoyl moiety $(\mathrm{m} / \mathrm{z}, 121)$ and the further loss of the methoxy group producing the tropylium ion $(\mathrm{m} / \mathrm{z}$ 91). These transitions are not very specific, and can come from any compound with a methoxybenzoyl moiety, however as there were no other transitions available for these compounds, they had to be used as quantification and confirmation transitions. Regarding the ILIS, only a single transition was monitored.

The chromatographic separation was initially based on a mobile phase composed of water: $\mathrm{MeOH}$, which resulted in very poor peak shapes. Different concentrations of ammonium acetate buffer and $\mathrm{pH}$ (formic acid) were investigated and the effects of $\mathrm{pH}$ and mobile phase ionic strength on the peak shapes, resolution and efficiencies were evaluated by varying the buffer concentration. An optimal mobile phase consisting of water with $5 \mathrm{mM}$ ammonium acetate and $0.01 \%$ formic acid (solvent $\mathrm{A}$ ) and $\mathrm{MeOH}$ with $0.01 \%$ formic acid (solvent B) was finally selected.

\subsection{Optimisation of extraction procedure}

An investigation into the filtration losses of these compounds was made in samples at both natural and $\mathrm{pH} 2$, using a vacuum filter (Whatman, $0.45 \mu \mathrm{m}$ mixed cellulose ester membrane). It was found that for naphyrone and the 25-X-NBOMe compounds, less than $5 \%$ of the compounds were recovered following filtration, while for MDPV a recovery of $55-71 \%$ was found. (Table S1) With these results, filtration was not employed in this method, instead only centrifugation. 
Two cartridges were evaluated in the optimisation of the SPE procedure: Oasis HLB and Oasis MCX, which are two of the most popular cartridges for the extraction of different types of illicit drugs in environmental waters (Baker and Kasprzyk-Hordern, 2011). The backbone of the Oasis sorbents consists of apolar moieties (benzyl groups, aliphatic chains) and polar groups (pyrrolidone). HLB is only synthesised from these two monomers and is neutral. MCX has extra sulfonic acid functional groups $(1.01 \mathrm{mmol} / \mathrm{g})$ implemented at a fixed location and contain permanently charged groups at any relevant $\mathrm{pH}$ (Bäuerlein et al., 2012).For both cartridges, $100 \mathrm{~mL}$ of IWW was spiked with the compounds (100 ng/L) before and after extraction and the recovery was used to determine the better cartridge for further optimisation. No $\mathrm{pH}$ adjustment was made for the Oasis HLB cartridges, while for the MCX, samples were acidified ( $\mathrm{pH} 2$ ) in order to protonate the basic analytes, thereby enhancing their ionic interactions with the sorbent (Senta et al., 2015). This led to a reduction in matrix interferences, giving higher sensitivity and peak shapes for the majority of the compounds (Figure S2). The SPE procedure followed for the HLB cartridges was the same as in previously published studies. (Bade et al., 2015; Bijlsma et al., 2014)

Higher recoveries were obtained when using Oasis MCX cartridges (Figure S3) and therefore these were selected for further optimisation. For the washing step, water, pure $\mathrm{MeOH}$ and acidified $\mathrm{MeOH}(\mathrm{pH}$ 2) were tested. Drying under vacuum (or not) was also tested, to determine the optimal washing/drying steps (Figure S3).

As seen in Figure S3, the optimal SPE procedure involved washing with $5 \mathrm{~mL}$ acidified 
In previous methods for NPS using MCX cartridges, different percentages of ammonia in methanol have been used for elution, ranging from $0.5 \%$ to $4 \%$ (Kinyua et al., 2015a; Reid et al., 2014; Senta et al., 2015; van Nuijs et al., 2013). A compromise of $2 \%$ was utilised in this work, and showed good recoveries for all compounds. An elution volume of $5 \mathrm{~mL}$ of $2 \%$ ammonia in $\mathrm{MeOH}$ solution was finally chosen. This was based on the comparison of the recoveries of $5 \mathrm{~mL}$ and $10 \mathrm{~mL}$ elution volumes, with recoveries only $2 \%$ less for the $5 \mathrm{~mL}$ than the $10 \mathrm{~mL}$.

\subsection{Method Validation}

267

Before applying the developed methodology to IWW samples, the method was fully

validated for linearity, precision and accuracy (recovery), LOD, LOQ and q/Q ratio

(Tables 1 and 2). A calibration curve of seven points was made in solvent from 0.5-100 ng/L (in triplicate). Correlation coefficients were greater than 0.99 for all compounds, except for naphyrone and the NBOMe compounds, which had values between 0.970.98. For precision and accuracy, blank IWW samples were spiked at four concentration levels (1 ng/L, $5 \mathrm{ng} / \mathrm{L}, 10 \mathrm{ng} / \mathrm{L}$ and $50 \mathrm{ng} / \mathrm{L})$, and analysed in quintuplicate. These two sets correspond to the different LOQs of some of the compounds (either1 ng/Lor $5 \mathrm{ng} / \mathrm{L}$, see Table 1). Accuracy was measured by means of recovery, with all compounds showing satisfactory recovery (between 70-120\%), and precision (all within RSD 20\%).

LOQs were estimated from a non-statistical point of view, utilising an LOQ objective: the lowest level in sample for which the method was fully validated in terms of accuracy and precision. This criterion has been utilised in the past in published results (Bijlsma et al., 2009) and is used in other fields, such as pesticide residue analysis (SANCO, 2013). This gives a more realistic LOQ value, albeit generally higher than those estimated from statistical criteria (i.e. signal-to-noise of 10 at the lowest validation 
level tested); thus, comparison of LOQs reported in the literature for different analytical methods is commonly difficult due to the distinct criteria applied by the authors.

Average intensity $\mathrm{q} / \mathrm{Q}$ ratios were calculated from reference standards in solvent of different concentrations (Table 1). With RSD\% values $\leq 11 \%$ for all $\mathrm{q} / \mathrm{Q}$ ratios, there was high confidence that the ratios are not concentration dependent. These were compared to those experimentally obtained from sample extracts spiked at the lowest level validated. The aim of this was to test the robustness of these values and to check for potential matrix interferences that could affect the q/Q ratios and consequently, the confirmation process. As Table 2 shows, average q/Q deviations were all below 30\% (SANCO, 2013), except for 25-I-NBOMe and 25-C-NBOMe at the lowest level of 1 ng/L. This finding returns to the previous discussion of the non-specificity of the NBOMe transitions, whereby although these transitions could be seen at this level, matrix interferences let the $\mathrm{q} / \mathrm{Q}$ deviations far exceed the threshold of the SANCO guidelines, which were being followed in this work. This led to the LOQ for these two compounds being increased to $5 \mathrm{ng} / \mathrm{L}$.

Matrix effects are a known drawback of LC-MS/MS, which can adversely affect the compounds of interest, leading to signal enhancement or suppression, thereby affecting the quantification process. These effects are most pronounced in more complex matrices, such as IWW. In this work, matrix effects were calculated by comparing the peak areas of Set 1 (SPE eluates (IWW previously extracted) spiked with the mixed standard and ILIS solutions) with Set 2 (mixed standard solution in solvent, including ILIS). All samples were performed in triplicate and averaged to perform the following calculations (Matuszewski et al., 2003):

Matrix effects $(\%)=\frac{\text { average peak area }(\text { Set } 1)}{\text { average peak area }(\text { Set } 2)} \times 100$ 
307 These calculations showed the true impact of the matrix on the compounds, with all 308 showing significant matrix enhancement (Table 2). To correct for these interferences, 309 ILIS were included in the calculation:

310 Matrix effects $(\%)=\frac{\text { average peak area }(\text { Set } 1, \mathrm{ILIS}) / \text { average peak area (Set 2,ILIS) }}{\text { average peak area }(\text { Set } 1) / \text { average peak area }(\text { Set } 2)} \times 100$

311 Including ILIS to the calculations led to corrected matrix effects under $10 \%$ for all 312 compounds.

313 Additional data pertaining to the use of ILIS is shown in Table 2, for SPE recovery and 314 matrix effects, showing how well the ILIS are able to correct for matrix interferences. 
Stability of analytes is a matter of concern in any analysis, particularly when dealing with very low analyte concentrations in complex matrices such as wastewater. It is imperative that target analytes do not degrade during the 24-hour composite samples collection or during their storage before extraction. Composite samples are normally collected at $4{ }^{\circ} \mathrm{C}$ and are stored either at that temperature, or at $-20^{\circ} \mathrm{C}$, depending on the time lapsing between collection and extraction(Senta et al., 2015), while extraction is usually carried out at room temperature. For these reasons, the stability of the target analytes in this study was studied at $4{ }^{\circ} \mathrm{C},-20^{\circ} \mathrm{C}$ and $20^{\circ} \mathrm{C}$. The study was carried out in both raw and filtered wastewater (as some research groups filter their samples prior to storage) as well as in Milli-Q water. Furthermore, the impact of acidification was also examined, with the samples examined at both natural $\mathrm{pH}$ and at $\mathrm{pH} 2$.

In this section, low (60-100\% transformation), medium (20-60\% transformation) and high stability (0-20\% transformation) is defined as by McCall et al(McCall et al., 2016), with all results being normalised to $t=0$. It must be stated that there was little difference between the filtered and unfiltered wastewater for most analytes, with the compounds temperatures, for at least 7 days.

The results show that if the samples are not acidified they should be refrigerated (at $4^{\circ} \mathrm{C}$ ), or frozen (at $-20^{\circ} \mathrm{C}$ ), and analysed within 7 days to ensure that no significant degradation occur. Alternatively, if samples are acidified to $\mathrm{pH} \mathrm{2,} \mathrm{all} \mathrm{investigated}$ compounds are more stable and can even be maintained at room temperature for up to 7 days. However, after 30 days, there were some distinct stability issues with some 
compounds: mephedrone, methedrone and butylone all exhibiting low stability (up to $84 \%$ transformation); N-ethylcathinone, MDPV and methylone showing medium stability while the 25-X-NBOMe compounds and naphyrone still had high stability (less than 10\% transformation) (Figure 1). All other results of the stability tests (i.e. in raw unacidified wastewater as well as both acidified and unacidified filtered wastewater and Milli-Q water) can be found in the supporting information (Figures S4-S7). These results also mirror those of the recent studies of Senta et al(Senta et al., 2015), and Reid et al (Reid et al., 2014), who investigated the stability of some of these compounds.

Although compounds were found to be stable at $\mathrm{pH} 2$ and $-20^{\circ} \mathrm{C}$ for at least one week, storage at lower temperatures have advantages in terms of green and sustainability analytical chemistry such as energy and cost saving. Furthermore, storage at $-20^{\circ} \mathrm{C}$ is sometimes limited and not always feasible for wastewater treatment plants and/or laboratories. In this regard, storage at $4^{\circ} \mathrm{C}$ is possible for at least one week as tested in the current study.

\subsection{Application to Real Samples}

A selection of samples from throughout Europe were investigated for the presence of NPS. In total, IWW from eight cities were investigated: Bristol, United Kingdom; Brussels, Belgium; Castellon, Spain; Oslo, Norway; Copenhagen, Denmark; Milan, Italy; Utrecht, The Netherlands and Zurich, Switzerland, with samples from weekends (Saturday and Sunday) and weekdays (Monday-Friday).

In every sequence of analysis, water samples were injected between two calibration curves. Two quality control samples (QCs), i.e. a blank water sample (previously analyzed) spiked at LOQ and 10×LOQ levels, were also analysed. QC recoveries were considered satisfactory when they were in the range of $70-120 \%$ for each analyte. 
363 As shown in Table 3, mephedrone was the most commonly identified NPS, with 364 concentrations ranging from $<5 \mathrm{ng} / \mathrm{L}$ (Brussels, Oslo, Copenhagen and Utrecht) to 106 $365 \mathrm{ng} / \mathrm{L}$ (Bristol). The high concentrations found in Bristol are similar to another study in 366 the United Kingdom, which found concentrations up to $114( \pm 15)$ ng/L. (Castrignanò et 367 al., 2016) These data also follow that from the UNODC, whereit is stated that 368 mephedrone has the highest prevalence rate of any NPS in the United 369 Kingdom(UNODC, 2014). The only other compounds confirmed in our study were 370 methylone and MDPV, with concentrations ranging from below LOQ to $12 \mathrm{ng} / \mathrm{L}$ 371 (methylone) and $6 \mathrm{ng} / \mathrm{L}$ (MDPV), with these low concentrations in line with previous 372 studies in Croatia and Switzerland (Kinyua et al., 2015a; Senta et al., 2015). These 373 overall results are also comparable with EMCDDA seizure data, with mephedrone 374 (20\%), methylone (7\%) and MDPV (9\%) some of the most commonly seized synthetic 375 cathinones. Furthermore, the United Kingdom had one of the most synthetic cathinone 376 seizures in Europe, implying a high consumption of these NPS (EMCDDA, 2015b).

377 Figure 2 shows the confirmation of MDPV, mephedrone and methylonein three IWW samples. All show the compliance of all the necessary criteria: retention time compatibility with the standard (in the form of the QC), at least two transitions, and ion ratio within $30 \%$ for at least one confirmation transition. It must be noted that the q2/Q

381 ratio for both MDPV and methylone are outside the accepted $\pm 30 \%$ ion ratio window, but as the q1/Q ratio for both are within the window, both can be confirmed. 
384

With quantification methods, it is easy to distinguish positive findings from negative, using strict criteria such as ion ratio $( \pm 30 \%)$, retention time $( \pm 0.1 \mathrm{~min})$ and at least one additional, confirmatory transition. However, there are some scenarios where the rulings are not so obvious.

For some compounds, only one, the most sensitive, transition may be observed, but may not be confirmed with a subsequent transition, suggesting that the compound could be present, although only at very low concentrations. If criteria are not strictly adhered to, this could lead to false positive findings. This was the case for MDPV in a sample from Zurich (Figure S8). Within this sample, the Q transition was found at the correct retention time, but the two q transitions were between 0.09-0.2 minutes away. This suggests that two different compounds were present in the samples showing the above transitions. Even though the shift in retention time itself is enough to reject the detection of this compound, the ion ratios were still checked. The q1 transition was found within the q/Q ratio threshold (30\%). Although the q2 ratio was more than $100 \%$ lower than expected, if the sample was not well checked, it could have been erroneously assigned as a false positive on the basis of one $\mathrm{q} / \mathrm{Q}$ ratio accomplishment.

Figure S8 also shows the curious case of butylone, which seemed to have been detected in an IWW sample from Bristol. As this figure shows, all three transitions can clearly be seen, albeit at a retention time 0.17 minutes lower than in the quality control. Although one $\mathrm{q} / \mathrm{Q}$ ratio is within the $\pm 30 \%$ threshold, the fact that the retention time is greater than 0.10 minutes from the standard is enough evidence to say that this is not butylone. However, with all the same transitions present, there is a possibility that this compound could be related to butylone. Due to the retention time being less than the reference 
407 standard, this compound could be a metabolite, which, due to its more polar 408 characteristics would lead it to elute earlier. Alternatively, it could be a related 409 cathinone-derivative, for example ethylone, which has the same fragmentation, and has 410 been found in previous European samples (Kinyua et al., 2015a). However, more 411 research is needed to confirm its identity.

412 
414 A very sensitive analytical method based on UHPLC-MS/MS has been developed for

415 the determination of ten NPS of the synthetic cathinone and phenethylamine classes in

416 influent wastewater. The overall analytical procedure, based on an off-line SPE step

417 using Oasis MCX cartridges prior to the determination by UHPLC-MS/MS using a

418 triple quadrupole analyzer, has been fully validated, obtaining satisfactory accuracy and

419 precision. Extra emphasis was made on the SPE cartridge, clean-up step and matrix

420 effects. An additional study was also made into the stability of these compounds in five

421 matrices at $-20^{\circ} \mathrm{C}, 4^{\circ} \mathrm{C}$ and $20^{\circ} \mathrm{C}$, with advice given on the optimal means of storage.

422 The method was tested on samples from throughout Europe, with mephedrone,

423 methylone and MDPV able to be identified in various samples. These data support the

424 applicability of the method to influent wastewaters, despite the very low concentrations

425 observed, and also support the previous information available on NPS use in Europe,

426 where these compounds are in agreement with prevalence and seizure data.

427 In the future, with information on flow data for the IWW plants and metabolic data to 428 correct for excretion, this method could be used to obtain accurate analytical 429 concentrations which subsequently could allow the estimation of NPS consumption 430 within a population.

\section{Contributions}

432 Richard Bade (RB), Lubertus Bijlsma (LB), Juan V. Sancho (JVS) and Félix 433 Hernández(FH) planned and designed the study. LB, Jose. A. Baz-Lomba, Sara 434 Castiglioni, Erika Castrignanò, Ana Causanilles, Emma Gracia-Lor, Barbara Kasprzyk435 Hordern, Juliet Kinyua, Ann-Kathrin McCall, Alexander L.N. van Nuijs, Christoph Ort, 436 Benedek G. Plósz, Pedram Ramin, Nikolaos I. Rousis, Yeonsuk Ryu, Kevin V. Thomas, 
437 Pim de Voogt and Ettore Zuccato organised the collection of the wastewater samples.

$438 \mathrm{RB}$ and $\mathrm{LB}$ developed the method and RB performed the validation. RB analysed the 439 samples and interpreted the results with contribution from all co-authors. RB, with 440 significant contributions from LB, JVS and FH drafted the manuscript, which was 441 critically revised by all co-authors. All authors are aware of the content, and accept 442 responsibility, for the manuscript. 


\section{Acknowledgements}

444 The authors would like to thank all the personnel of the wastewater treatment plants for 445 their collaboration in providing the samples: Sociedad de Fomento Agrícola 446 Castellonense (FACSA, Castellon, Spain), VEAS (Oslo, Norway), Aquiris (Brussels, 447 Belgium), Hoogheemraadschap de Stichtse Rijnlanden (Utrecht, the Netherlands), 448 Wessex Water (Bristol, UK), Metropolitana Milanese (Milan, Italy), Werdhölzli 449 (Zurich, Switzerland) and BIOFOS (Copenhagen, Denmark).

450 RB, JBL, EC, AC, JK, AKM, PR and NIR acknowledge the European Union for their 451 Early Stage Researcher (ESR) contracts and EGL for her Experienced Researcher (ER) 452 contract as part of the EU-International Training Network SEWPROF (Marie CuriePEOPLE Grant \#317205).

LB acknowledges NPS-Euronet (HOME/2014/JDRUG/AG/DRUG/7086), co-funded by 455 the European Union, for his post-doctoral fellowship. This publication reflects the views 456 only of the authors, and the European Commission cannot be held responsible for any 457 use which may be made of the information contained therein. AvN acknowledges the support of the Flanders Foundation for Research (FWO). EGL is also thankful for the financial support from Generalitat Valenciana (APOSTD/2015, Programa VALi+d).

460 The financial support of Generalitat Valenciana (Prometeo II 2014/023) and of the 461 Spanish Ministry of Economy and Competitiveness (Project ref CTQ2015-65603) is 462 also acknowledged by the authors of University Jaume I. 


\section{References}

Bade, R., Rousis, N.I., Bijlsma, L., Gracia-Lor, E., Castiglioni, S., Sancho, J. V., Hernandez, F., 2015. Screening of pharmaceuticals and illicit drugs in wastewater and surface waters of Spain and Italy by high resolution mass spectrometry using UHPLC-QTOF MS and LC-LTQ-Orbitrap MS. Anal. Bioanal. Chem. 407, 89798988. doi:10.1007/s00216-015-9063-X

Baker, D.R., Kasprzyk-Hordern, B., 2011. Critical evaluation of methodology commonly used in sample collection, storage and preparation for the analysis of pharmaceuticals and illicit drugs in surface water and wastewater by solid phase extraction and liquid chromatography-mass spectrometry. J. Chromatogr. A 1218, 8036-8059. doi:10.1016/j.chroma.2011.09.012

Bäuerlein, P.S., ter Laak, T.L., Hofman-Caris, R.C.H.M., de Voogt, P., Droge, S.T.J., 2012. Removal of charged micropollutants from water by ion-exchange polymers Effects of competing electrolytes. Water Res. 46, 5009-5018. doi:10.1016/j.watres.2012.06.048

Baz-Lomba, J.A., Reid, M.J., Thomas, K. V., 2016. Target and suspect screening of psychoactive substances in sewage-based samples by UHPLC-QTOF. Anal. Chim. Acta 914, 81-90. doi:10.1016/j.aca.2016.01.056

Bijlsma, L., Beltrán, E., Boix, C., Sancho, J. V, Hernández, F., 2014. Improvements in analytical methodology for the determination of frequently consumed illicit drugs in urban wastewater. Anal. Bioanal. Chem. 406, 4261-4272. doi:10.1007/s00216014-7818-4

Bijlsma, L., Sancho, J. V, Pitarch, E., Ibanez, M., Hernandez, F., 2009. Simultaneous ultra-high-pressure liquid chromatography-tandem mass spectrometry determination of amphetamine and amphetamine-like stimulants, cocaine and its metabolites, and a cannabis metabolite in surface water and urban wastewater. J. Chromatogr. a 1216, 3078-3089. doi:10.1016/j.chroma.2009.01.067

Borova, V.L., Gago-Ferrero, P., Pistos, C., Thomaidis, N.S., 2015. Multi-residue determination of 10 selected new psychoactive substances in wastewater samples by liquid chromatography-tandem mass spectrometry. Talanta 144, 592-603. doi:10.1016/j.talanta.2015.06.080

Caspar, A.T., Helfer, A.G., Michely, J.A., Auwarter, V., Brandt, S.D., Meyer, M.R., Maurer, H.H., 2015. Studies on the metabolism and toxicological detection of the new psychoactive designer drug 2-(4-iodo-2,5-dimethoxyphenyl)-N-[(2methoxyphenyl)methyl]ethanamine (25I-NBOMe) in human and rat urine using GC-MS, LC-MS, and LC-HR-MS/MS. Anal Bioanal Chem 6697-6719. doi:10.1007/s00216-015-8828-6

Castrignanò, E., Lubben, A., Kasprzyk-Hordern, B., 2016. Enantiomeric profiling of chiral drug biomarkers in wastewater with the usage of chiral liquid chromatography coupled with tandem mass spectrometry. J. Chromatogr. A 1438, 84-99. doi:10.1016/j.chroma.2016.02.015

Chen, C., Kostakis, C., Irvine, R.J., White, J.M., 2013. Increases in use of novel synthetic stimulant are not directly linked to decreased use of 3,4-methylenedioxyN-methylamphetamine (MDMA). Forensic Sci. Int. 231, 278-283. 
Elliott, S., Evans, J., 2014. A 3-year review of new psychoactive substances in casework. Forensic Sci. Int. 243, 55-60. doi:10.1016/j.forsciint.2014.04.017

EMCDDA, 2015a. European Drug Report: Trends and Developments.

EMCDDA, 2015b. New psychoactive substances in Europe. EU early Warn. Syst. 12. doi: $10.2810 / 372415$

Ibáñez, M., Pozo, Ó.J., Sancho, J. V., Orengo, T., Haro, G., Hernández, F., 2016. Analytical strategy to investigate 3,4-methylenedioxypyrovalerone (MDPV) metabolites in consumers' urine by high-resolution mass spectrometry. Anal. Bioanal. Chem. 408, 151-164. doi:10.1007/s00216-015-9088-1

Ibáñez, M., Sancho, J. V., Bijlsma, L., van Nuijs, A.L.N., Covaci, A., Hernández, F., 2014. Comprehensive analytical strategies based on high-resolution time-of-flight mass spectrometry to identify new psychoactive substances. TrAC Trends Anal. Chem. 57, 107-117. doi:10.1016/j.trac.2014.02.009

Kamata, H.T., Shima, N., Zaitsu, K., Kamata, T., Miki, A., Nishikawa, M., Katagi, M., Tsuchihashi, H., 2006. Metabolism of the recently encountered designer drug, methylone, in humans and rats. Xenobiotica 36, 709-723. doi:10.1080/00498250600780191

Kankaanpää, A., Ariniemi, K., Heinonen, M., Kuoppasalmi, K., Gunnar, T., 2014. Use of illicit stimulant drugs in Finland: A wastewater study in ten major cities. Sci. Total Environ. 487, 696-702. doi:10.1016/j.scitotenv.2013.11.095

Kinyua, J., Covaci, A., Maho, W., McCall, A.-K., Neels, H., van Nuijs, A.L.N., 2015 a. Sewage-based epidemiology in monitoring the use of new psychoactive substances: Validation and application of an analytical method using LC-MS/MS. Drug Test. Anal. 7, 812-818. doi:10.1002/dta.1777

Kinyua, J., Negreira, N., Ibáñez, M., Bijlsma, L., Hernández, F., Covaci, A., van Nuijs, A.L.N., 2015b. A data-independent acquisition workflow for qualitative screening of new psychoactive substances in biological samples. Anal. Bioanal. Chem. 407, 8773-8785. doi:10.1007/s00216-015-9036-0

Lai, F.Y., Erratico, C., Kinyua, J., Mueller, J.F., Covaci, A., van Nuijs, A.L.N., 2015. Liquid chromatography-quadrupole time-of-flight mass spectrometry for screening in vitro drug metabolites in humans: investigation on seven phenethylamine-based designer drugs. J. Pharm. Biomed. Anal. 114, 355-375. doi:10.1016/j.jpba.2015.06.016

Mardal, M., Meyer, M.R., 2014. Studies on the microbial biotransformation of the novel psychoactive substance methylenedioxypyrovalerone (MDPV) in wastewater by means of liquid chromatography-high resolution mass spectrometry/mass spectrometry. Sci. Total Environ. 493, 588-595. doi:10.1016/j.scitotenv.2014.06.016

Matuszewski, B.K., Constanzer, M.L., Chavez-Eng, C.M., 2003. Strategies for the assessment of matrix effect in quantitative bioanalytical methods based on HPLCMS/MS. Anal. Chem. 75, 3019-3030. doi:10.1021/ac020361s 
McCall, A.-K., Bade, R., Kinyua, J., Lai, F.Y., Thai, P.K., Covaci, A., Bijlsma, L., van Nuijs, A.L.N., Ort, C., 2016. Critical review on the stability of illicit drugs in sewers and wastewater samples. Water Res. 88, 933-947. doi:10.1016/j.watres.2015.10.040

Meyer, M.R., Du, P., Schuster, F., Maurer, H.H., 2010. Studies on the metabolism of the $\alpha$-pyrrolidinophenone designer drug methylenedioxy-pyrovalerone (MDPV) in rat and human urine and human liver microsomes using GC-MS and LC-highresolution MS and its detectability in urine by GC-MS. J. Mass Spectrom. 45, 1426-1442. doi:10.1002/jms.1859

Mwenesongole, E.M., Gautam, L., Hall, S.W., Waterhouse, J.W., Cole, M.D., 2013. Simultaneous detection of controlled substances in waste water. Anal. Methods 5, 3248-3254. doi:10.1039/c3ay40655e

Ort, C., van Nuijs, A.L.N., Berset, J.-D., Bijlsma, L., Castiglioni, S., Covaci, A., de Voogt, P., Emke, E., Fatta-Kassinos, D., Griffiths, P., Hernández, F., GonzálezMariño, I., Grabic, R., Kasprzyk-Hordern, B., Mastroianni, N., Meierjohann, A., Nefau, T., Östman, M., Pico, Y., Racamonde, I., Reid, M., Slobodnik, J., Terzic, S., Thomaidis, N., Thomas, K. V, 2014. Spatial differences and temporal changes in illicit drug use in Europe quantified by wastewater analysis. Addiction 109, 1338-1352. doi:10.1111/add.12570

Poklis, J.L., Nanco, C.R., Troendle, M.M., Wolf, C.E., Poklis, A., 2014. Determination of 4-bromo-2,5-dimethoxy-N-[(2-methoxyphenyl)methyl]-benzeneethanamine (25B-NBOMe) in serum and urine by high performance liquid chromatography with tandem mass spectrometry in a case of severe intoxication. Drug Test. Anal. 6, 764-769. doi:10.1002/dta.1522

Pozo, Ó.J., Sancho, J. V., Ibáñez, M., Hernández, F., Niessen, W.M. a., 2006. Confirmation of organic micropollutants detected in environmental samples by liquid chromatography tandem mass spectrometry: Achievements and pitfalls. TrAC Trends Anal. Chem. 25, 1030-1042. doi:10.1016/j.trac.2006.06.012

Reid, M., Thomas, K., 2016. New Psychoactive Substances: analysis and site-specific testing, in: Castiglioni, S. (Ed.), Assessing Illicit Drugs in Wastewater: Advances in Wastewater-Based Drug Epidemiology. pp. 57-65.

Reid, M.J., Derry, L., Thomas, K. V., 2014. Analysis of new classes of recreational drugs in sewage: Synthetic cannabinoids and amphetamine-like substances. Drug Test. Anal. 6, 72-79. doi:10.1002/dta.1461

SANCO, 2013. Guidance document on analytical quality control and validation procedures for pesticides residues in food and feed [WWW Document]. SANCO /12571/2013. URL http://ec.europa.eu/food/plant/pesticides/guidance_documents/docs/qualcontrol_en. pdf

Senta, I., Krizman, I., Ahel, M., Terzic, S., 2015. Multiresidual analysis of emerging amphetamine-like psychoactive substances in wastewater and river water. J. Chromatogr. A 1425, 204-212. doi:10.1016/j.chroma.2015.11.043

Tang, M.H., Ching, C.K., Tsui, M.S., Chu, F.K., Mak, T.W., 2014. Two cases of severe intoxication associated with analytically confirmed use of the novel psychoactive 
substances 25B-NBOMe and 25C-NBOMe. Clin Toxicol 52, 561-565. doi:10.3109/15563650.2014.909932

Thomas, K. V, Bijlsma, L., Castiglioni, S., Covaci, A., Emke, E., Grabic, R., Hernández, F., Karolak, S., Kasprzyk-Hordern, B., Lindberg, R.H., Lopez de Alda, M., Meierjohann, A., Ort, C., Pico, Y., Quintana, J.B., Reid, M., Rieckermann, J., Terzic, S., van Nuijs, A.L.N., de Voogt, P., 2012. Comparing illicit drug use in 19 European cities through sewage analysis. Sci. Total Environ. 432, 432-439. doi:10.1016/j.scitotenv.2012.06.069

UNODC, 2014. Global Synthetic Drugs Assessment: Amphetamine-type stimulants and new psychoactive substances.

Uralets, V., Rana, S., Morgan, S., Ross, W., 2014. Testing for designer stimulants: Metabolic profiles of 16 synthetic cathinones excreted free in human urine. J. Anal. Toxicol. 38, 233-241. doi:10.1093/jat/bku021

van Nuijs, A.L.N., Gheorghe, A., Jorens, P.G., Maudens, K., Neels, H., Covaci, A., 2013. Optimization, validation, and the application of liquid chromatographytandem mass spectrometry for the analysis of new drugs of abuse in wastewater. Drug Test. Anal. 861-867. doi:10.1002/dta.1460 


\section{Figure Captions:}

613 Figure 1: Stability of all compounds in raw $\mathrm{IWW}$ at $(\mathrm{pH} 2)$ at $20^{\circ} \mathrm{C}(\mathrm{TOP}), 4^{\circ} \mathrm{C}$ 614 (MIDDLE) and $-20^{\circ} \mathrm{C}$ (BOTTOM). Transformation (y axis) shows the value of the 615 analyte remaining (i.e. a value of $20 \%$ means a transformation of $80 \%$ ). The acceptable 616 interval of $70-120 \%$ has also been included (black lines).

617 Figure 2: Positive findings (from left to right) of MDPV, mephedrone and methylone in 618 IWW of Milan, Bristol and Copenhagen, respectively. The uppermost transition for 619 each compound is the confirmation (Q) transition in the QC (low, $5 \mathrm{ng} / \mathrm{L}$ ), while the 620 lower three are all from the sample. All include three transitions, and the $\mathrm{q} / \mathrm{Q}$ ratio, 621 together with the deviation from the QC. 
Figure 1:
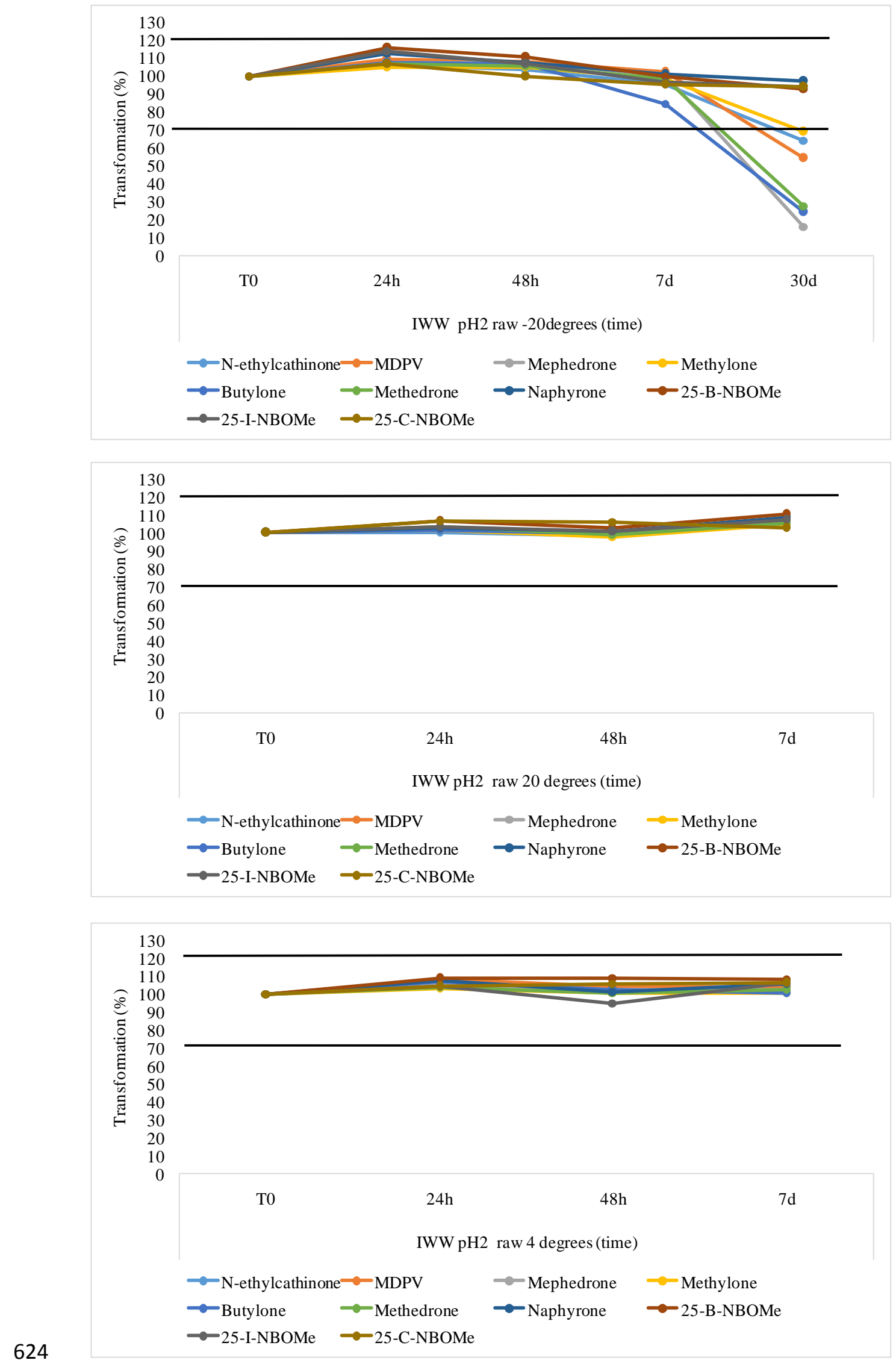

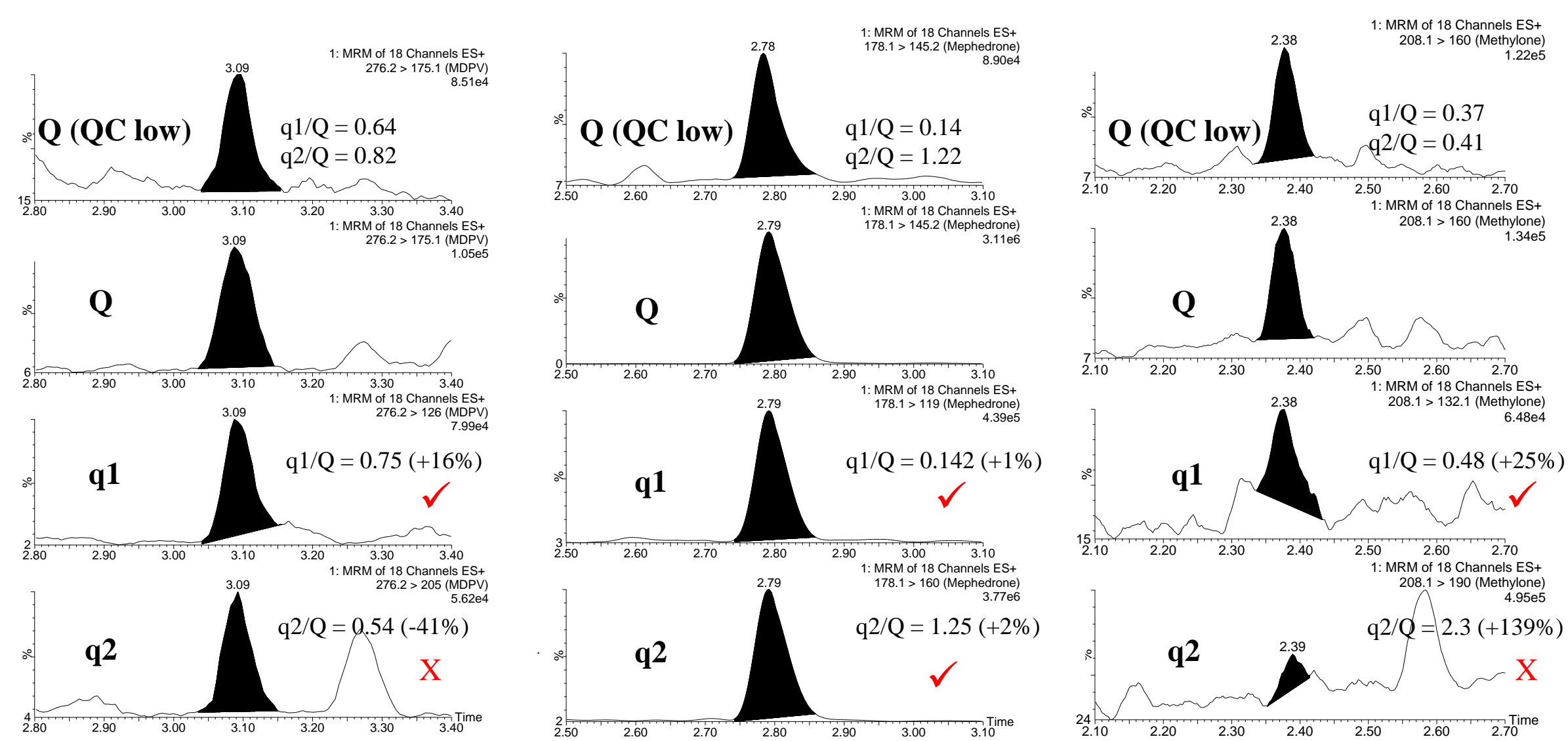
Table 1: MS/MS optimised conditions for all studied compounds

\begin{tabular}{|c|c|c|c|c|c|c|c|c|}
\hline Compound & $\begin{array}{c}\text { Retention } \\
\text { time } \\
\text { (mins) }\end{array}$ & $\begin{array}{c}\text { Precursor } \\
\text { ion } \\
{[\mathbf{M}+\mathbf{H}]^{+}} \\
(\mathbf{m} / \mathbf{z})\end{array}$ & $\begin{array}{c}\text { Cone } \\
\text { Voltage } \\
\text { (V) }\end{array}$ & $\begin{array}{c}\text { Collision } \\
\text { Energy } \\
(\mathbf{e V})\end{array}$ & $\begin{array}{c}\text { Product } \\
\text { Ions } \\
(\mathbf{m} / \mathbf{z})\end{array}$ & $\begin{array}{l}\mathrm{LOQ}^{\mathrm{a}} \\
(\mathrm{ng} / \mathrm{L})\end{array}$ & $\begin{array}{c}\mathbf{L O D}^{\mathrm{b}} \\
\left(\operatorname{pg} \mathbf{L}^{-1}\right)\end{array}$ & $\begin{array}{l}\text { q/Q ratio } \\
\text { (RSD \%) }\end{array}$ \\
\hline \multirow[t]{2}{*}{ 25-B-NBOMe } & 3.76 & 380.1 & 40 & 20 & 121.0 & 1 & 100 & \\
\hline & & & & 30 & 91.0 & & & $0.4(6)$ \\
\hline \multirow[t]{2}{*}{ 25-C-NBOMe } & 3.70 & 336.1 & 20 & 20 & 121.1 & 5 & 70 & \\
\hline & & & & 40 & 91.0 & & & $0.6(6)$ \\
\hline \multirow[t]{2}{*}{ 25-I-NBOMe } & 3.86 & 428.1 & 20 & 20 & 121.0 & 5 & 100 & \\
\hline & & & & 50 & 91.0 & & & $0.5(6)$ \\
\hline \multirow[t]{3}{*}{ Butylone } & 2.68 & 222.1 & 20 & 20 & 174.0 & 5 & 200 & \\
\hline & & & & 20 & 146.0 & & & $0.3(6)$ \\
\hline & & & & 30 & 131.2 & & & $0.3(7)$ \\
\hline \multirow[t]{3}{*}{ Mephedrone } & 2.77 & 178.1 & 30 & 20 & 145.2 & 5 & 200 & \\
\hline & & & & 20 & 119.0 & & & $0.1(11)$ \\
\hline & & & & 10 & 160.0 & & & $1.3(7)$ \\
\hline \multirow[t]{2}{*}{ Methedrone } & 2.57 & 194.1 & 20 & 20 & 161.1 & 5 & 200 & \\
\hline & & & & 20 & 146.0 & & & $0.4(4)$ \\
\hline MDPV & 3.11 & 276.2 & 50 & 20 & 175.1 & 1 & 200 & \\
\hline
\end{tabular}




\begin{tabular}{|c|c|c|c|c|c|c|c|c|}
\hline & & & & 20 & 126.0 & & & $0.6(5)$ \\
\hline & & & & 20 & 205.0 & & & $0.8(9)$ \\
\hline \multirow[t]{3}{*}{ Methylone } & 2.36 & 208.1 & 50 & 20 & 160.0 & 5 & 50 & \\
\hline & & & & 20 & 132.1 & & & $0.4(6)$ \\
\hline & & & & 10 & 190.0 & & & $0.5(11)$ \\
\hline \multirow[t]{3}{*}{ Naphyrone } & 3.71 & 282.2 & 50 & 20 & 141.2 & 1 & 50 & \\
\hline & & & & 20 & 211.1 & & & $0.5(6)$ \\
\hline & & & & 40 & 127.4 & & & $0.2(6)$ \\
\hline \multirow[t]{3}{*}{ N-ethylcathinone } & 2.42 & 178.1 & 20 & 10 & 130.0 & 5 & 200 & \\
\hline & & & & 20 & 117.1 & & & $1.1(7)$ \\
\hline & & & & 30 & 160.1 & & & $0.7(10)$ \\
\hline 25-B-NBOMe-d 3 & 3.76 & 383.3 & 40 & 20 & 124.0 & & & \\
\hline 25-C-NBOMe-d 3 & 3.70 & 339.1 & 20 & 20 & 124.0 & & & \\
\hline $25-\mathrm{I}-\mathrm{NBOMe}-\mathrm{d}_{3}$ & 3.86 & 431.1 & 20 & 20 & 124.0 & & & \\
\hline Butylone-d 3 & 2.68 & 225.1 & 20 & 20 & 177.1 & & & \\
\hline Mephedrone- $\mathrm{d}_{3}$ & 2.77 & 181.1 & 30 & 20 & 145.2 & & & \\
\hline MDPV- $\mathrm{d}_{8}$ & 3.11 & 284.2 & 50 & 20 & 205.0 & & & \\
\hline Methylone- $\mathrm{d}_{3}$ & 2.36 & 211.1 & 50 & 20 & 163.1 & & & \\
\hline Naphyrone- $\mathrm{d}_{5}$ & 3.71 & 287.2 & 50 & 20 & 141.2 & & & \\
\hline
\end{tabular}

${ }^{\text {a}} \mathrm{LOQ}$ objective. Lowest concentration tested for the method being fully validated with satisfactory results.

629 bOD estimated for a signal-to-noise level of three from the quantification SRM chromatogram of blank samples spiked at the lowest analyte concentration tested. 
Table 2: Method validation for all compounds in IWW at 2 validation levels (all values are in \%), together with recovery and matrix effects before and after correction with

\begin{tabular}{|c|c|c|c|c|c|c|c|c|c|c|c|}
\hline \multirow[t]{2}{*}{ Compound } & \multicolumn{2}{|c|}{$\begin{array}{c}\text { Matrix effects } \\
(\%)^{\mathrm{a}}\end{array}$} & \multicolumn{2}{|c|}{ q1/Q ratio } & \multicolumn{2}{|c|}{$\mathrm{q} 2 / \mathrm{Q}$ ratio } & \multicolumn{4}{|c|}{ SPE Recovery (\%) } & \multirow[t]{2}{*}{ Linearity } \\
\hline & & & Low $^{b}$ & $\operatorname{High}^{\mathrm{c}}$ & Low $^{b}$ & $\mathrm{High}^{\mathrm{c}}$ & Low $^{b}$ & & $\mathrm{High}^{\mathrm{c}}$ & & \\
\hline & & No ILIS & & & & & & No ILIS & & No ILIS & \\
\hline 25-B-NBOMe & -4 & 60 & $-11(12)$ & $-9(4)$ & - & - & $106(7)$ & $87(13)$ & $104(4)$ & $89(16)$ & 0.9722 \\
\hline 25-I-NBOMe & -6 & 66 & $5(8)$ & $-13(1)$ & - & - & $98(9)$ & $85(16)$ & $103(6)$ & $86(16)$ & 0.9722 \\
\hline Butylone & -6 & 29 & $-13(12)$ & $-4(6)$ & $24(26)$ & $-11(4)$ & $100(10)$ & $91(13)$ & $101(4)$ & $89(8)$ & 0.9923 \\
\hline MDPV & -7 & 48 & $6(8)$ & $10(4)$ & $17(13)$ & $9(8)$ & $98(10)$ & $94(8)$ & $98(9)$ & $91(10)$ & 0.9900 \\
\hline Mephedrone & -9 & 26 & $-6(11)$ & $12(4)$ & $0(5)^{d}$ & $15(4)^{d}$ & $94(10)$ & $90(8)$ & $97(7)$ & $85(6)$ & 0.9914 \\
\hline Methedrone & -10 & 31 & $-12(4)$ & $-7(6)$ & - & - & $103(8)$ & $83(7)$ & $104(5)$ & $87(7)$ & 0.9923 \\
\hline Methylone & -6 & 30 & $6(7)$ & $-1(8)$ & $\mathrm{d}$ & $\mathrm{d}$ & $101(8)$ & $93(4)$ & $101(4)$ & $84(7)$ & 0.9919 \\
\hline Naphyrone & -10 & 62 & $-5(5)$ & $-7(9)$ & $-5(9)$ & $-13(3)$ & $108(10)$ & $86(10)$ & $101(8)$ & $87(15)$ & 0.9883 \\
\hline N-ethylcathinone & 3 & 27 & $-33(21)$ & $1(7)$ & $\mathrm{d}$ & $5(6)^{d}$ & $96(7)$ & $74(12)$ & $98(7)$ & $83(5)$ & 0.9975 \\
\hline
\end{tabular}

ILIS (Isotopically-labelled Internal Standard)

a: for matrix effects, a negative value (-) denotes matrix suppression, while positive values indicate matrix enhancement.

b: Low refers to the LOQ value of all compounds: $1 \mathrm{ng} / \mathrm{L}$ for MDPV, Naphyrone and 25-B-NBOMe and $5 \mathrm{ng} / \mathrm{Lfor}$ all other compounds

c: High refers to the 10xLOQ value of all compounds: $10 \mathrm{ng} / \mathrm{L}$ for MDPV, Naphyrone and 25-B-NBOMe and $50 \mathrm{ng} / \mathrm{Lfor}$ all other compounds

d: These transitions were for a loss of water. The non-specificity associated with these transitions combined with the complex IWW matrix led to some of these transitions being non-observed/interfered. However, as they were all q2 transitions, the method could still be validated based on q1. 
Table 3: Concentrations (in ng/L) of investigated NPS in IWW throughout Europe (weekday/weekend)

\begin{tabular}{|l|c|c|c|c|c|c|c|c|}
\hline Compound & Bristol & Brussels & Castellon & Copenhagen & Milan & Oslo & Utrecht & Zurich \\
\hline N-ethylcathinone & - & - & - & - & - & - & - & - \\
\hline MDPV & - & - & - & - & $-/ 3$ & $-/ 2$ & - & $6 /-$ \\
\hline Mephedrone & $61 / 106$ & $\mathrm{~d} /-$ & - & $5 / 5$ & - & $\mathrm{d} / \mathrm{d}$ & $-/ \mathrm{d}$ & $-/ \mathrm{d}$ \\
\hline Methylone & $-/ \mathrm{d}$ & - & - & $-/ 12$ & - & - & $7 / 5$ & - \\
\hline Butylone & - & - & - & - & - & - & - & - \\
\hline Methedrone & - & - & - & - & - & - & - & - \\
\hline Naphyrone & - & - & - & - & - & - & - & - \\
\hline 25-B-NBOMe & - & - & - & - & - & - & - & - \\
\hline 25-I-NBOMe & - & - & - & - & - & - & - & - \\
\hline 25-C-NBOMe & - & - & - & - & - & - & - & - \\
\hline
\end{tabular}

639 d: detected, at a concentration below LOQ; -: not detected (<LOD)

640

641 